Os anos de aprendizado filosófico de Johann
Wolfgang Goethe

\author{
Márcio Suzuki
}

Professor do Departamento de Filosofia da USP e pesquisador do CNPq 

Não é inapropriado dizer que existe em Goethe uma imagem negativa da teoria e também da filosofia. Não são poucas as afirmações nesse sentido espalhadas por sua vasta obra, e não é preciso muito esforço de memória para lembrar os versos que Mefistófeles diz ao jovem pedante na primeira parte do Fausto ("Cinza, caro amigo, é toda teoria/E verde a dourada árvore da vida”), nem aqueles em que o próprio Fausto enumera todas as ciências que estudou, e que foram por ele abandonadas como inúteis.

No que diz respeito às relações de Goethe com a filosofia, a leitura de um livro antigo pode nos ajudar a repensar a questão. No início do século XX, Karl Vorländer, neokantiano da escola de Marburg, escreveu um trabalho no qual procurou mostrar o quanto o escritor e seu amigo Schiller teriam sofrido a influência da filosofia de Kant, o mais "eminente" de todos os filósofos recentes, como registra Eckermann em conversa com o poeta datada de 11 de abril de $1827^{1}$.

Lendo tanto a primeira (influência de Kant sobre Schiller) como a segunda parte do livro (influência dele sobre Goethe), percebe-se logo que Vorländer força um pouco a mão. Toda referência desabonadora à filosofia kantiana é minimizada, e, em alguns casos, ele tenta mostrar que a fonte não é confiável, ou até sugerir erros de impressão ou de interpretação ${ }^{2}$. No entanto, ele tem clareza sobre o que não pode fazer. Diferentemente do que ocorre com Schiller (embora também nesse caso a afirmação seja problemática), ele sabe que não pode dizer que o poeta foi um kantiano, nem no "sentido estrito, e nem mesmo no sentido amplo da palavra"3. Ele prefere dizer que Goethe foi um "Jünger" de Kant, termo que quer dizer "discípulo" ou até "apóstolo". Difícil

1 K. VORLÄNDER. Kant, Schiller, Goethe. 2. ed. Leipzig: Meiner, 1923, p. 237.

2 Caso, por exemplo, da desconfiança em relação ao relato de Riemer, no qual se afirma que Kant teria trazido os escolásticos de volta e que "ceticismo, kantismo ou criticismo só podiam surgir do protestantismo” (id., ibid., p. 201). Também passa em silêncio a rejeição contundente da noção kantiana de "mal radical".

3 Id., ibid., p. 258. 
imaginar que o autor do Fausto tenha sido uma coisa ou outra, a menos que se possa ver em Kant exemplo de uma das "definições" que ele propõe para a figura do "mestre": "Chamamos com justiça nossos mestres àqueles de quem sempre aprendemos. Nem todo aquele de quem aprendemos merece esse título"4.

Apesar desses problemas, o livro é uma obra instrutiva, principalmente se os documentos que apresenta puderem ser lidos não de uma perspectiva kantiana, mas goethiana. E essa leitura parece quase se impor. É que os materiais que ele fornece constroem involuntária e quase imperceptivelmente no espírito do leitor a história de uma formação filosófica, à qual, parafraseando o título consagrado, poderia se chamar "Os anos de aprendizado filosófico de Johann Wolfgang Goethe"s.

Não há dúvida de que Goethe teve muito contato com a filosofia. Ao final do livro, o autor nos convida a visitar aquela que seria a "oficina filosófica do poeta", a sua biblioteca filosófica, com 176 títulos abrangendo mais de 200 volumes. Uma consulta ao índice onomástico no final da obra também causará espanto pelo número de nomes citados (embora o livro também se refira a Schiller, a imensa maioria dos filósofos referidos foi mencionada por Goethe). Isso deixa claro que o autor do Werther empenhou-se bastante no estudo de diversos outros autores além do filósofo de Königsberg.

Os capítulos em que se divide o livro, e que compõem a história da formação filosófica goethiana, são os seguintes:

Primeira Parte. Desenvolvimento filosófico de Goethe antes de seu contato com Schiller: os primeiros estudos filosóficos de Goethe antes do surgimento da filosofia crítica (1764/65-1781); do surgimento da filosofia crítica até a publicação da Crítica do juízo

4 J. W. von. GOETHE. Maximen und Reflexionen. Frankfurt am Main: Insel, 1982. Ed. de Max Hecker, p. 40.

5 Também nos inspiramos aqui no título Anos de aprendizado filosófico, que Friedrich SCHLEGEL deu aos seus cadernos de reflexões sobre filosofia (Anos de aprendizado filosófico. 2 v. Munique: Schöningh, 1963. Ed. de Ernst Behler). 
(1781-1790); da publicação da Crítica do juízo até o contato duradouro com Schiller (1791-1794).

Segunda Parte. Schiller, Kant, Goethe (1794-1805).

Terceira Parte. Da morte de Schiller até os últimos dias de Goethe: estudos filosóficos de Goethe, manifestações sobre filósofos e relações com eles (1805-1816); estudos kantianos no ano de 1817; testemunhos da relação de Goethe com a filosofia, em particular com a filosofia kantiana, no período final de sua vida (1818-1831).

O que Goethe leu de filosofia nos anos de 1764 a 1781? Filósofos populares: Sulzer (voltará a ler na Itália), Mendelssohn (não é tão mau quanto parece) e Garve (de quem tirou ideias importantes para o Wilhelm Meister). É a época da inegável importância de Espinosa. Relações muito próximas com o filósofo importante que é Jacobi, além de Hamann e Herder.

Em 1788, Goethe volta da Itália e passa por uma crise pessoal. Até então Kant não fazia parte do repertório de seus autores. Poucos se lembram, mas a primeira edição da Crítica da razão pura, de 1781, não teve nenhum êxito de público. As coisas modificam-se com a segunda edição, em 1787, quando Goethe ainda está na Itália.

Em carta de 18 de fevereiro de 1789 enviada ao filósofo Reinhold, um dos primeiros a reconhecer e defender publicamente o valor da Crítica, o poeta Christoph Martin Wieland, seu sogro, lhe diz: "Há algum tempo Goethe tem estudado a Crítica de Kant com grande aplicação e tomou a decisão de ir ter com o Senhor em Jena uma longa conferência sobre ela"6. Nesta mesma carta, Wieland afirma que o escritor Karl Philipp Moritz, grande amigo de Goethe, é também admirador de Reinhold. Goethe lê com aprovação o texto que Reinhold escreve neste mesmo ano, "Sobre os destinos da filosofia kantiana até agora", publicado no Mercúrio 
Alemão (gazeta literária de grande divulgação na época, editada pelo sogro). Reinhold escreve a Kant dizendo do interesse de Wieland e de Goethe pelo artigo que acabara de publicar.

No ano seguinte, o poeta lê a Crítica do juízo. O seu exemplar, assim como o da Crítica da razão pura, registra as passagens que sublinhou e anotou. Interessante é a maneira peculiar com que parece ter lido as duas obras. Vorländer assinala a opinião comum de dois amigos, Körner e Schiller, a respeito da curiosa interpretação que ele dava aos textos. Körner escreve a Schiller (em 6 de outubro de 1790) dizendo que Goethe "tem encontrado muito alimento para a filosofia dele" na Terceira Crítica. Körner diz "seine Philosophie". Dias mais tarde ( $1^{\circ}$ de novembro) Schiller descreve o encontro com Goethe em sua casa em Dresden:

Goethe esteve conosco ontem em casa, e a conversa logo versou sobre Kant. É interessante como ele veste tudo a seu jeito e maneira próprios, e como devolve de modo surpreendente o que leu... Tampouco sua filosofia [seine Philosophie] me agrada de todo: ela colhe demais no mundo sensível, enquanto eu colho na alma. Em geral, seu modo de representar é demasiadamente sensível e, para mim, muito tateante. Mas seu espírito atua e investiga em todas as direções e se esforça para construir um todo, e isso faz dele, para mim, um grande homem? .

Körner responde concordando que ele procede de um jeito "demasiadamente sensível" na filosofia, mas acrescenta que "isso é bom para você e para mim... a fim de que não venhamos a nos perder tão longe no plano intelectual"'. Goethe emitirá mais tarde a mesma opinião: a filosofia, a abstração, teria atrapalhado a poesia de Schiller.

Kant foi o assunto principal do primeiro encontro dos dois escritores na casa de Schiller, mas não houve prosseguimento da amizade entre eles. Quatro anos mais tarde isso aconteceu. 
Schiller residia agora em Jena, e, assim como da primeira vez, o tema da conversa foi novamente Kant. O encontro é chamado de "acontecimento feliz" por Goethe, e foi narrado pelo próprio. Os dois estão saindo da reunião de julho de 1794 da Sociedade dos Cientistas Naturais de Jena. Começam a conversar sobre o modo de atuar da natureza. Chegando à frente da casa de Schiller, este o convida a entrar. O convidado lhe apresenta a sua doutrina da metamorfose das plantas e tenta lhe rascunhar o esboço de uma planta simbólica. Schiller ouve atentamente, e, quando a exposição acaba, diz: "Isso não é uma experiência, mas uma Ideia". Goethe vê surgir novamente em si a "velha raiva", mas se controla, e a conversa prossegue proveitosamente. O poeta retomará mais tarde esse "início feliz" dizendo que nos dez anos seguintes a convivência dos dois pôde desenvolver paulatinamente as "disposições filosóficas” que existiam em sua natureza. Esse "progresso" filosófico é difícil de ser descrito, afirma, pois não se trata de "níveis de formação" (Bildungsstufen), mas de caminhos cheios de erros, de percalços e desvios, como num salto não premeditado, porém vivo, para um "nível mais alto de cultura". Formação (Bildung) para Goethe não é um caminho cumulativo, retilíneo e progressivo, mas cheio de sinuosidades e erros?.

Aqui começa propriamente sua iniciação à filosofia kantiana. Schiller, que se iniciara no conhecimento de Kant por intermédio de Körner e de Reinhold, seria então, nas palavras de Vorländer, o especialista, o homem de ofício, em contato com quem Goethe perderá a ingenuidade filosófica. Descrevendo o seu jeito de proceder em filosofia, ele mesmo viria mais tarde a confirmar o diagnóstico de Körner e Schiller: "Quando eu filosofava sobre objetos à minha maneira, eu o fazia com ingenuidade inconsciente e acreditava realmente que via minhas opiniões diante de meus olhos" ${ }^{\prime \prime}$. 
Na mesma época, ele mantém forte contato com os irmãos Humboldt, que também haviam se aproximado da filosofia kantiana. A partir de então, o aprendizado filosófico incluirá não só a leitura da maioria dos livros publicados por Kant no período (A religião nos limites da simples razão, Antropologia de um ponto de vista pragmático, O conflito das faculdades, os Princípios metafísicos da ciência natural etc.), e algumas obras do período pré-crítico, mas também outros autores de menos renome, sem contar o mainstream idealista, Fichte, Schelling, Hegel e Schopenhauer.

É difícil resumir e pôr em sequência todos os livros e autores estudados por Goethe. Ele possuía, por exemplo, um exemplar anotado do Conceito da doutrina-da-ciência, de Fichte. Leu a sua Doutrina do direito. Leu as Ideias para uma filosofia da natureza e provavelmente A alma do mundo, de Schelling, em 1798 (mesmo com algumas objeções), e a Introdução à filosofia da natureza (1799). À queixa de Schiller sobre a taciturnidade de Schelling (há tempos eles não conversam sobre nada interessante, limitando-se a jogar cartas uma vez por semana), Goethe responde: isso não é raro, é muito difícil ter pessoas com quem a gente se forme e a quem possamos formar ${ }^{11}$. A expressão, de difícil tradução, é significativa (daß man sich mit- und aneinander bildet), e central na ideia goethiana de formação - entendida como formação conjunta, recíproca, em que os companheiros, preservando suas diferenças individuais, trocam livre e generosamente suas experiências literárias, artísticas, filosóficas, em suma, suas experiências de vida. Amigos, diz a "Introdução aos Propileus", são aqueles que convivem e têm interesse em se desenvolver progressivamente (sich fortschreitend auszubilden), visando fins parecidos ${ }^{12}$. Já bem mais tarde, saudoso da antiga amizade intelectual e afetiva com

11 Carta a Schiller, 22 de dezembro de 1798 (J. W. von GOETHE. Der Briefwechsel zwischen Schiller und Goethe. Frankfurt am Main: Insel, 1999, p. 721).

12 Idem. Ästhetische Schriften 1771-1805. In: J. W. von. GOETHE. Sämtliche Werke, Briefe, Tagebücher und Gespräche. v. 18. Frankfurt am Main: DKV, 1998, p. 459. 
Schiller, e buscando um companheiro com quem pudesse continuar a filosofar, ele falará do desejo de dar prosseguimento àquela "formação em conjunto" (gemeisame Bildung), que ele compara à criação de uma "grande obra de arte" ${ }^{13}$.

Isso lembra o procedimento de "filosofar ou poetizar em conjunto" que os românticos de Jena levaram adiante naqueles mesmos anos: abandono do filosofar solitário, em "estado de natureza”, para um filosofar coletivo, cultivado, artístico. Uma “época inteiramente nova das ciências e artes” começaria, diz Schlegel, quando "naturezas que se complementam reciprocamente fizessem [bildeten] obras em conjunto"14. Goethe comenta que Schiller, Schelling, Niethammer e ele filosofaram muito juntos em Jena (wird oft zusammen... philosophiert, 1799). Niethammer, que Goethe conheceu em 1798, era amigo de Hölderlin, Hegel e Schelling, com os quais havia estudado no seminário de Tübingen. Foi aluno de Fichte, tornou-se professor de Filosofia em Jena e editor do Jornal Filosófico. É com Niethammer que Goethe tem inúmeros colloquia em Jena. Colloquium é conversa científica, encontro de especialistas, mas também "aula particular". $\mathrm{Na}$ mesma época, Goethe diz que conversa com Niethammer e Friedrich Schlegel sobre idealismo transcendental, com Ritter sobre física especulativa ${ }^{15}$. Parece que assistiu, escondido atrás das cortinas, a aulas do filósofo da natureza Steffens em Halle. Também leu outro filósofo da natureza, Baader. E também conversou com Fries e Schleiermacher.

As descrições desses encontros lembram muito os exercícios de desenho e modelagem que Goethe faz, sob a orientação de vários artistas plásticos, durante sua viagem à Itália. O aprendizado filosófico é similar ao aprendizado artístico: seguindo a norma

${ }_{13}$ Carta a Christian Heinrich Schlosser, 19 de fevereiro de 1815 (J. W. von GOETHE. Der Briefwechsel..., op. cit.).

${ }_{14}$ F. SCHLEGEL. Fragmentos do Athenäum, 125. In: F. SCHLEGEL. O dialeto dos fragmentos. São Paulo: Iluminuras, 1997, p. 67.

15 K. VORLÄNDER. Kant..., op. cit., p. 186. 
paradoxal do ideário neoclássico, também na filosofia é preciso observar que, quanto mais mestres o aprendiz imita, mais chances ele tem de se tornar original. A diferença entre o aprendizado artístico e o aprendizado filosófico é apenas de ordem temporal. Ao se dedicar ao estudo do desenho de paisagem e da modelagem, Goethe ainda não havia abdicado da ideia de se tornar artista. Quando começa os estudos filosóficos, talvez já estivesse claro para ele qual era de fato o seu campo de atuação. É por isso que às vezes ele nos passa a impressão - reforçada sempre pela insistência de Schiller neste sentido - de que está perdendo tempo com a filosofia (mas ele diz algo parecido em relação às artes). Ele não se tornará filósofo, a abstração do pensamento filosófico não é para ele. Mas, de certo modo, é ele quem instiga à especulação, como escreve a Schiller em 19 de novembro de 1800 :

Onde é que a pobre poesia deverá por fim buscar refúgio, eu não sei; aqui ela corre novamente perigo de ser posta de lado por filósofos, cientistas naturais e consortes. Mas, certo, não posso negar que sou eu mesmo quem convida e exige a presença desses senhores e acaba se deixando levar pelo mau hábito de teorizar por vontade própria e, portanto, não posso me queixar de ninguém além de mim mesmo ${ }^{16}$.

Por que ele insiste no "mau hábito"? Goethe reclama que não consegue se manter "puramente na especulação" (rein spekulativ). Ele sempre busca, a cada proposição filosófica, uma "intuição e, por isso, sempre se refugia na natureza" ${ }^{17}$. Esta vai ser a tônica do seu discurso antifilosófico. Mas é preciso não esquecer o quanto sua intuição e a natureza na qual busca refúgio também estão marcadas pela filosofia.

Uma coisa, no entanto, é certa: se todo esse aprendizado teve algum resultado, Goethe não pode ser considerado mero auto- 
didata ou diletante em filosofia. É patente a semelhança de sua argumentação contra o diletantismo com os argumentos da Crítica do juízo: diletante é aquele que quer juntar, sem nenhuma mediação, técnica e fantasia ${ }^{18}$. A imaginação deve ser regrada pela técnica, pela arte: "nada mais terrível do que imaginação sem gosto" ${ }^{19}$.

Goethe estabelece uma diferença importante entre "sistema filosófico" e "pensamento filosófico", que explica por que ele nunca se declarou definitivamente por um sistema. Desde Jacobi e a "Querela sobre o Ateísmo", as coisas já haviam sido postas de uma maneira muito clara na Alemanha. O único sistema de filosofia possível é o dogmático e, mais precisamente, o sistema espinosano. Herder, seu amigo e mentor na juventude, já antes havia sido acusado do pior erro filosófico que se pode cometer, o de querer conciliar sistemas diferentes. Ele caiu no erro do ecletismo. Goethe continuará a defender algo próximo da posição herderiana, o que aparentemente tiraria dele a condição de grande pensador filosófico. É aqui que ele introduz outra distinção importante:

Não pode haver uma filosofia eclética, mas sim filósofos ecléticos.

Eclético, porém, é qualquer um que, naquilo que o cerca, naquilo que acontece ao seu redor, apropria-se do que é conforme a sua natureza; e é neste sentido que é preciso considerar tudo o que se chama de formação e de progresso, sejam eles tomados em termos teóricos ou em termos práticos $^{2 \circ}$.

Não existe filosofia eclética, mas há filósofos ecléticos como Herder, cuja Bildung consiste exatamente na apropriação constante daquilo que o cerca e toca. Bem compreendido, o ecletismo se torna uma posição incontornável: há tantas coisas entre o céu e a terra, que são poucos os "órgãos" desenvolvidos para captá-las.

18 J. W. von GOETHE, J. W. von. Maximen..., op. cit., 1127, p. 194.

19 Id., ibid., 507, p. 104-5.

20 J. W. von GOETHE, J. W. von. Maximen..., op. cit., 648 e 649, p. 128. 
É nesse sentido que se deve entender também a famosa profissão de fé goethiana, encontrada numa carta ao filósofo Jacobi de 6 de novembro de 1813 :

Eu, de minha parte, diante das diversas direções de meu ser, não posso me contentar com uma só maneira de pensar; como poeta e artista, sou politeísta; em compensação, como cientista natural, sou panteísta, e uma coisa tão decididamente quanto a outra. Se careço de um deus para minha personalidade como homem moral, também isso já está resolvido.

Com sua iniciação filosófica, Goethe pôde compreender todo o alcance da mudança radical na maneira de pensar introduzida pela filosofia crítica. É como se ele dissesse, e diz, de certo modo: não somos mais os mesmos depois da revolução copernicana de Kant. Esta talvez seja a maior homenagem que um não filósofo de profissão poderia prestar ao grande filósofo seu contemporâneo.

O sentido em que ele diz isso é claro: só o filisteu recusa a filosofia de seu tempo. Também os grandes espíritos que tentam furtar-se a ela ou recusá-la sem armas à altura, também estes são tragados pela história. Tema certamente hegeliano. Mas Goethe o concebe antes (e diferentemente) de Hegel.

Embora tenha buscado um tom conciliador e apaziguador, não deve ter causado pouco impacto na época ouvir o que Goethe escreveu no seu discurso em memória ao poeta Wieland, sogro do kantiano Reinhold: nos seus primeiros escritos, Kant teria estado próximo de Wieland e da filosofia popular, mas, quando ergueu seu "gigantesco edifício doutrinal", aqueles que até então filosofavam ou faziam poesia "despreocupados da vida", como Wieland e seu grupo, viram ali uma ameaça real ${ }^{21}$. Isso porque as três críticas teriam instituído um saber mais elevado, um agir ético mais firme e um gosto baseado em leis universais, o que teria afastado todo

21 Algo semelhante é dito no depoimento bem conhecido de Heinrich von Kleist sobre o terremoto provocado pela crítica kantiana. 
prazer individual, toda "formação contingente" e toda peculiaridade ligada a um povo. Essa mudança radical deu realmente início a uma nova época também na poesia - época, portanto, "que tinha de estar em contradição com nosso amigo [Wieland], e vice-versa" ${ }^{22}$.

A crítica surgida do kantismo foi implacável: mesmo que o gosto antiquado de Kant o tenha levado a mencionar Wieland como exemplo de grande poeta na Crítica do juízo, não tardaram a surgir apreciações desfavoráveis a ele, depois de instaurado o novo regime de pensamento. Essa apreciação de Goethe, escrita em 1813, tem um precedente não menos interessante na apresentação que escreveu à edição das obras de Winckelmann, em 1805. Ali se pode ler:

[...] tendo presente no espírito os acontecimentos dos tempos recentes, aqui é o lugar certo de inserir uma observação que pudemos fazer no curso de nossa vida: nenhum homem de letras renegou o grande movimento filosófico iniciado por Kant, não se opôs a ele ou o desprezou impunemente $[\ldots]$

A avaliação é a mesma, só que, com Winckelmann, ocorreu algo diferente. Nenhum homem de letras e de interesse pelas coisas do espírito escapou impunemente ao idealismo transcendental, “[...] com exceção dos genuínos investigadores da Antiguidade, que parecem ter sido favorecidos, bem acima de todos os outros homens, pela peculiaridade de seu estudo"23.

O trecho não deixa dúvida. Diferentemente do que aconteceu com o poeta Wieland e seu grupo, os "genuínos investigadores da Antiguidade" passaram impunes pelo tribunal filosófico kantiano. O que eles tiveram a seu favor para não ser condenados? A fim de 
responder a essa pergunta, é preciso lembrar uma diferença importante da concepção de Goethe em relação ao ideal renascentista do homem, tal como é descrito por Jacob Burckhardt em seu livro sobre A civilização do Renascimento na Itália. Burckhardt, como é sabido, caracteriza o uomo universale do Renascimento como indivíduo capaz não apenas de aprender diversas artes, mas também de introduzir novidades em seu exercício. Outra distinção importante é aquela entre homens de formação apenas multifacetada (vielseitig) e o homem de formação total ou universal (allseitig), cujo melhor exemplo é Leon Battista Alberti²4. Embora Goethe tenha tido várias aptidões (desenho, poesia, ciência natural) e tenha buscado se educar em várias frentes, ele não é um humanista, sua concepção antropológica não pode ser assimilada ao humanismo renascentista, como tantas vezes se afirmou. Estar atento a essa diferença é crucial para a compreensão do significado da ideia de formação nele. Ao fim de seus anos de aprendizado, Wilhelm Meister descobre que não tem vocação para ser o ator que acreditava ser, erro, entretanto, capital em sua trajetória. A decisão de se casar e se tornar médico não pode ser vista como conformismo, como filistinismo da parte do seu criador, censura que lhe foi feita pelo romantismo, acentuada em Hegel e no marxismo. Assumir uma função pública, trabalhar numa profissão em benefício da sociedade, é inteiramente condizente com a "filosofia" goethiana e faz parte do sentido de formação, como mostrou Ernst Cassirer numa conferência intitulada "A ideia de Goethe sobre Formação e Educação”. Vai também nessa direção a observação precisa de H. J. Schrimpf sobre um dos sentidos de vida em Goethe: "vida significa: cuidar dos outros..." 25.

A formação goethiana parece paradoxal por estes dois aspec-

24 J. BURCKHARDT. Die Kultur der Renaissance in Italien. Leipzig : Kröner, 1928, p. 128 e ss.

25 H. J. SCHRIMPF. Das Weltbild des späten Goethes. Überlieferung und Bewahrung in Goethes Alterswerk. Stuttgart : Kohlhammer, 1956, p. 106. 
tos: ela é formação individual e até certo ponto burguesa, mas também cuidado dos outros; é busca de completude e, ao mesmo tempo, exigência de limitação, de especialização. Goethe sabia muito bem que sua época era a da divisão do trabalho. E o próprio Wilhelm Meister, na carta que escreve a seu cunhado Werner explicando-lhe a decisão de deixar a carreira de negociante e se tornar ator, exprime de maneira peculiar a percepção de que sua vida terá de transcorrer sob o signo da especialização. Enquanto o nobre pode, pelo nascimento, desfrutar de certo desenvolvimento universal em sua pessoa, pois em princípio lhe é possível ascender a qualquer posição social, não lhe sendo dado, portanto, "nenhum limite", o burguês tem "o puro sentimento tácito da linha demarcatória que lhe foi traçada" ${ }^{26}$. Isso que pôde parecer resignação ou acomodação à visão limitada do burguês deve, portanto, ser interpretado com cuidado. O desenvolvimento do nobre já está feito em virtude da identidade de sua pessoa e sua posição, e, por isso, num certo sentido, só para os outros cidadãos é possível falar de educação e aprimoramento das aptidões - dentro dos limites que lhes estão de antemão traçados.

Por mais despropositada que a comparação possa parecer, a explicação de Wilhelm sobre o seu destino na carta ao cunhado ajuda de algum modo a compreender a trajetória de Winckelmann, e vice-versa. Por que o estudioso da Antiguidade conseguiu sair ileso do terremoto causado pela Crítica da razão pura? Winckelmann, sem dúvida, teve boa estrela, pois o ramo do conhecimento a que se dedicou já continha, em sua especificidade ou peculiaridade (Eigentümlichkeit), tudo aquilo que era preciso saber, ou seja, continha a totalidade, a universalidade no particular. E Goethe o explica:

Visto que [os estudiosos da Antiguidade] se ocupam unicamente daquilo livro $\mathrm{V}$, cap. 3. p. $657^{-8}$. 
que de melhor foi produzido pelo mundo, e só consideram o que há de menor e ruim em referência àquilo que se produziu de excelente, os seus conhecimentos alcançam tal plenitude, os seus juízos tal segurança, o seu gosto tal consistência, que parecem ter se aprimorado tanto no interior de seu próprio círculo, que causam admiração e mesmo espanto ${ }^{27}$.

O aprimoramento alcançado no estudo da arte antiga é de tal ordem, que ele transborda o próprio círculo a que está restrito. $\mathrm{O}$ autor da História da arte antiga pôde ter o seu século ("Winckelmann e seu século" é o título da apresentação de Goethe às obras dele) em pleno "século da crítica", porque sua produção tem algo de comparável desta vez ao modo de proceder do próprio Kant. A semelhança pode ser constatada quando se lê a Máxima 1198: "Kant se limita com deliberação num certo círculo, e sempre aponta ironicamente para além dele”28.

A maneira pela qual se olha para o filósofo e para o historiador da arte antiga é parecida, ambos são apreendidos como indivíduos cuja força se revela paradoxalmente em terem alcançado uma limitação. O limite é a própria manifestação da força, que, por isso mesmo, parece apontar além dele, como um excedente de significação que jamais pode ser esgotado. O historiador da arte causa admiração e espanto no interior de seu círculo; o filósofo remete sempre, ironicamente, para além do seu ${ }^{29}$. Os dois são simbólicos, na acepção plena do termo, exatamente como são simbólicos a planta primordial, o fenômeno originário e as grandes obras de arte.

Talvez agora a definição do mestre mencionada no início faça mais sentido: mestres são aqueles de quem sempre se aprende. $\mathrm{O}$ verdadeiro ensinamento deles vem menos da matéria que ensinam

27 J. W. von GOETHE. Winckelmann..., op. cit., p. 440.

28 "Kant beschränkt sich mit Vorsatz in einen gewissen Kreis und deutet ironisch immer darüber hinaus" (Idem. Maximen..., op. cit., p. 204).

29 Que a "ilimitação" só possa dar-se num círculo, em que o começo é fim, o fim, recomeço e o meio, manifesto, eis o tema do poema Unbegrenzt, cuja estrofe inicial, traduzida pelo professor Ruy Fausto, figura como epígrafe desta revista. 
do que da capacidade inesgotável que têm de fecundar e formar, ligada ao poder de se dar uma forma, isto é, de se fechar e limitar. Kant e Winckelmann são como os grandes artistas da Antiguidade e do Renascimento, e, menos que uma acomodação burguesa, o que Wilhelm Meister parece procurar é também uma forma de se tornar mestre, à sua maneira e no pequeno círculo que será o seu.

Goethe percebeu a afinidade de seu pensamento sobre a formação com o modo de Kant intuir o parentesco entre natureza e arte na Crítica do juízo. Ele reconheceu também que essa "lei" de toda formação expressa pela natureza e pela arte comporta, além disso, um ensinamento ético e moral. A maestria na limitação seria, sob esse aspecto, análoga àquilo que a moral kantiana preconiza com a ideia de que o uso da liberdade está condicionado pelo respeito à lei. A combinação desses elementos (natureza, arte, limite, formação, liberdade e lei) foi expressa num dos poucos sonetos que escreveu:

\section{Natureza e arte}

Natureza e arte parecem fugir uma da outra, E se encontram antes de nos termos dado conta;

Também em mim desapareceu toda aversão, E ambas parecem exercer a mesma igual atração.

De que não é capaz um pouco de honesta luta! Quando nas horas de nossa regrada labuta O espírito à arte se entrega com aplicação, A natureza volta a aquecer o coração.

Assim é toda formação, seja ela qual for:

Espíritos indômitos lutam inutilmente

Por perfeição da mais alta e pura intensidade.

Quem quer grandeza, as forças é bom recompor;

Na limitação, e não antes, se mostra o mestre,

E somente a lei pode nos dar liberdade. 
No escrito em que comenta o opúsculo de Kant "Que é Ilustração?”, e em que reconsidera a atualidade do pensamento iluminista, Michel Foucault escreve que a novidade filosófica do texto kantiano está em fazer uma reflexão sobre o hoje, sobre o momento presente "como diferença na história e como motivo para uma tarefa particular". Segundo Foucault, é a primeira vez que uma filosofia reúne três aspectos que até então não haviam estado juntos: Kant teria pensado "a significação da sua obra" no que concerne ao problema do conhecimento ligando-a a uma reflexão sobre a história e a uma "análise particular do momento singular em que ele escreve e por causa do qual escreve”. Posicionando sua obra diante de seu próprio tempo, Kant teria antecipado a atitude do sujeito moderno, a "atitude de modernidade", tal como encontramos em Baudelaire ${ }^{\circ}$.

Assim como Foucault, o autor do Wilhelm Meister teve, como se viu, consciência aguda da transformação representada pela filosofia kantiana. Mas, com toda essa consciência da importância histórica de Kant, e dentro de um presente já invadido pela modemidade (o poeta sobreviveu quase três décadas ao filósofo), Goethe rejeita justamente o modo pelo qual a filosofia kantiana (e, depois dela, o hegelianismo) compreende a relação dos homens com a história. Sua visão da história se compreende pelo retrato que faz de Winckelmann, o investigador da Antiguidade que, vivendo fora de seu tempo, teve forte impacto sobre os seus contemporâneos. E talvez não só sobre eles, mas também sobre aquele outro "filho de sua época" que, na geração seguinte, chegará igualmente a fazer "experiências extemporâneas" como "dis-

30 M. FOUCAULT. Qu'est-ce que les Lumières? In: M. FOUCAULT. Dits et écrits. Paris: Gallimard, 1994, IV, p. 568 e ss. Para um comentário desse texto, cf. R. R. TERRA. Foucault, leitor de Kant: da antropologia à ontologia do presente. In: R. R. TERRA. Passagens. Estudos sobre a filosofia de Kant. Rio de Janeiro: Editora da UFRJ, 2003. 
cípulo de tempos mais antigos, principalmente gregos”. Isso para lembrar a marca que Goethe deixou nas noções nietzschianas de "extemporaneidade" e "genealogia". Pois o "filólogo clássico por profissão" Nietzsche (como ele mesmo se descreve) também teve de admitir que o único sentido em que a filologia clássica pode agir em sua época é extemporaneamente (unzeitgemäss), isto é, “contra a época e, com isso, sobre a época e, oxalá, em prol de uma época vindoura" ${ }^{11}$.

A rejeição goethiana da ideia de história universal, da filosofia da história inaugurada por Kant, está expressa nos singelos quatro versos de "Quem vive na história universal" ${ }^{2}$. A vida se faz pelo mergulho no presente ("Só o presente é nossa felicidade") e nas outras dimensões do tempo ("Só quem olha para dentro dos tempos e aspira a estar dentro deles/É digno de poder falar e fazer poesia"). O breve poema contrapõe, assim, à vida "alienada" na temporalidade abstrata da história universal, a vida concreta e singular nas verdadeiras dimensões do tempo. E essa experiência pessoal da temporalidade é um dos muitos aspectos em que a poesia e a "filosofia" de Goethe mostram grande afinidade com a tradição dos exercícios espirituais das filosofias helenísticas, da qual era certamente conhecedor, como mostra Pierre Hadot no livro que dedicou ao poeta alemão33. Entre tantas outras coisas, Hadot refere nesse livro como Goethe cunhou a sentença "Não se esqueça de viver" em substituição ao adágio "Memento mori" ("Não se esqueça de que você vai morrer"), e concebeu uma forma de dizer sim à vida que antecipa, mais uma vez, a filosofia de Nietzsche.

31 F. NIETZSCHE. Unzeitgemässe Betrachtungen, II, Von Nutzen und Nachteil der Historie. In: F. NIETZSCHE. Kritische Studienausgabe. Munique : De Gruyter, 2003 , v. 1, p. 247.

$32 \mathrm{O}$ poema faz parte do ciclo Zahme Xenien (Xênias mansas). Há tradução para o português: J. W. von GOETHE. Poemas. Org. e trad. por P. Quintela. Coimbra (Port): Centelha, 1986, p. 156-7.

33 P. HADOT, P. N'oublie pas de vivre. Goethe et la tradition des exercices spirituels. Paris: Albin Michel, 2004. 
Uma passagem de Michel Foucault parece sugerir a mesma proximidade de Goethe com as filosofias antigas. No curso sobre a Hermenêutica do sujeito, Foucault introduz o termo Selbstbildung, como "cultura" ou "formação de si"34, a título de variação da locução "cuidado de si" (souci de soi), com a qual explica o trabalho de ascese e de exercício necessários para a constituição do sujeito nas filosofias antigas. Empregando a palavra alemã, ele abre conscientemente uma via de mão dupla: tanto o ideal de Bildung, de formação, como o entendiam Goethe e seus contemporâneos, pode ser considerado uma forma da ascese antiga, como o cuidado de si dos antigos pode remeter à constituição do sujeito nos tempos modernos. Nos dois casos, o sujeito seria o trabalho de constituição de si mesmo como "obra de arte".

Foi num procedimento parecido que Foucault aproximou, quase duas décadas antes, o Wilhelm Meister de Goethe da concepção antropológica de Kant. $\mathrm{Na}$ antropologia, assim como no romance de Goethe, Foucault encontra duas formas aparentadas de constituição do sujeito, que fariam parte daquela outra arqueologia que ele começou a construir no final da vida, uma arqueologia das "técnicas de si", cuja orientação era bem distinta da que governava as estratégias de dominação do outro35.

Em Goethe, o "cuidado" ou a "formação de si" não pode ser dissociado de um "cuidado dos outros" e, principalmente, de uma formação recíproca com os outros (como se viu na primeira parte). Ela deve ser entendida como uma transformação constante

34 M. FOUCAULT. L'herméneutique du sujet. Cours au Collège de France (1981-1982). Paris: Gallimard, 2001, p. 45-6.

$35 \mathrm{Na}$ passagem que aqui interessa, Foucault afirma que a Antropologia de Kant situa o homem no mundo, nessa escola que é o seu "elemento formador". Ela não é uma "história da cultura, nem análise sucessiva de suas formas", mas "uso", "prática ao mesmo tempo imediata e imperativa de uma cultura inteiramente dada", que "ensina o homem a reconhecer, em sua própria cultura, a escola do mundo”, o que a aproximaria do romance de formação de Goethe (M. FOUCAULT. Gênese e estrutura da Antropologia de Kant. Trad. de M. A. da Fonseca, S. T. Muchail. São Paulo: Loyola, 2011, p. 47). 
de si e daqueles aos quais se está ligado por quaisquer laços de intimidade e afinidade, sem esquecer, mais uma vez, que, muito antes de Nietzsche e Foucault, esse trabalho de transformação é identificado à criação de uma obra artística.

Também como Foucault, Goethe desconfia das mudanças espetaculares, das grandes revoluções, e acredita mais no amadurecimento lento, na mudança constante e miúda. O poeta Wieland tinha o mesmo sentimento quando se levantou contra a tirania da legislação universal que os franceses revolucionários quiseram impor aos anacrônicos pequenos estados alemães. E o camponês que fascina Goethe durante o cerco de Mainz também é uma figura emblemática. $\mathrm{O}$ conselheiro da corte parece descrevê-lo como o faria um pintor de cenas históricas. Diferentemente, no entanto, do carroceiro do Grito do Ipiranga de Pedro Américo, o camponês alemão nem sequer se volta para o campo de batalha, e continua a lavrar a terra, impassível, mesmo estando ao alcance dos canhões inimigos. "Esse homem sozinho e limitado", anota Goethe em seu diário, "não larga de suas ocupações mais imediatas", não se importando com o fato de que ali ao lado esteja acontecendo algo importante para a história ${ }^{36}$. Embora suas razões sejam diametralmente opostas, esse simples camponês e o grande filósofo da sua época têm uma posição estranhamente próxima diante dos acontecimentos históricos, pois Kant costumava a ensinar a seus alunos (e isso é crucial na sua distinção entre Historie e Geschichte) que as batalhas, ganhas ou perdidas, não farão diferença alguma no cômputo final da história universal ${ }^{37}$. Com sua experiência de observador direto da guerra, a posição de Goethe é diferente, e foi celebrizada na frase dita aos oficiais aliados durante a campanha na França, diante da resistência dos

36 Cf. o Tag- und Jahreshefte, de 1795 (J. W. von GOETHE, J. W. Gedenkausgabe. v. 12. Zurique: Artemis, 1949, p. 650).

37 Cf. I. KANT. Introdução ao curso de Antropologia Friedländer. Berlim: De Gruyter, 1997 (Ed. Akademie, v. XXV). 
franceses ao canhoneio em Valmy: "De aqui e de hoje em diante começa uma nova época da história do mundo, e vocês poderão dizer que estiveram presentes" ${ }^{8}$.

\section{Bibliografia}

BURCKHARDT, J. Die Kultur der Renaissance in Italien. Leipzig: Kröner, 1928.

FOUCAULT, M. Qu'est-ce que les Lumières?. In: FOUCAULT,

M. Dits et écrits. Paris: Gallimard, 1994.

. L'herméneutique du sujet. Cours au Collège de France (1981-1982). Paris: Gallimard, 2001. Ed. de A. Fontana, F. Gros. . Gênese e estrutura da Antropologia de Kant. Trad. de M. A. da Fonseca, S. T. Muchail. São Paulo: Loyola, 2011.

GOETHE, J. W. von. Campanha na França, de 19 de setembro de 1792. In: GOETHE, J. W. von. Gedenkausgabe. v. 12. Zurique: Artemis, 1949. Ed. de Ernst Beutler.

. Cerco de Mainz, de 28 de maio de 1792. In: GOETHE, J. W. von. Gedenkausgabe. v. 12. Zurique: Artemis, 1949. Ed. de Ernst Beutler.

. Tag- und Jahreshefte (1795). In: GOETHE, J. W. von. Gedenkausgabe. v. 12. Zurique: Artemis, 1949. Ed. de Ernst Beutler.

Zum brüderlichen Andenken Wieland's (1813). In: GOETHE, J. W. von. Gedenkausgabe. v. 12. Zurique: Artemis, 1949. Ed. de Ernst Beutler.

$3^{8}$ Cf. Campanha na França, de 19 de setembro de 1792 (J. W. von GOETHE. Gedenkausgabe. v. 12. Zurique: Artemis, 1949, p. 289). Cf. também a anotação de 28 de maio de 1792 do Cerco de Mainz (id., ibid., p. 428). 
GOETHE, J. W. von. Maximen und Reflexionen. Frankfurt am Main: Insel, 1982. Ed. de Max Hecker. . Poemas. Org. e trad. por P. Quintela. Coimbra: Centelha, 1986.

. Wilhelm Meister Lehrjahre. Frankfurt am Main : DKV, 1992.

Ästhetische Schriften 1771-1805. In: GOETHE, J. W. von. Sämtliche Werke, Briefe, Tagebücher und Gespräche. Frankfurt am Main: DKV, 1998.

. Der Briefwechsel zwischen Schiller und Goethe. Frankfurt am Main: Insel, 1999. Ed. de E. Staiger.

Winckelmann und sein Jahrhundert, edição citada.

HADOT, P. N'oublie pas de vivre. Goethe et la tradition des exercices spirituels. Paris: Albin Michel, 2004.

KANT, I. Introdução ao curso de Antropologia Friedländer. Berlim: De Gruyter, 1997. (Ed. Akademie, v. XXV).

NIETZSCHE, F. Unzeitgemässe Betrachtungen, II, Von Nutzen und Nachteil der Historie. In: NIETZSCHE, F. Kritische Studienausgabe. Munique: De Gruyter, 2003, v. 1. Ed. de G. Colli, M. Montinari.

SCHLEGEL, F. Kritische Ausgabe: philosophische Lehriahre 1796-1806. 2 v. Munique: Ferdinand Schöningh, 1963. Ed. de Ernst Behler.

. Fragmentos do Athenäum, 125. In: SCHLEGEL, F. O dialeto dos fragmentos. São Paulo: Iluminuras, 1997.

SCHRIMPF, H. J. Das Weltbild des späten Goethes. Überlieferung und Bewahrung in Goethes Alterswerk. Stuttgart: Kohlhammer, 1956.

TERRA, R. R. Foucault, leitor de Kant: da antropologia à ontologia do presente. In: TERRA, R. R. Passagens. Estudos sobre a filosofia de Kant. Rio de Janeiro: Editora da UFRJ, 2003.

VORLÄNDER, K. Kant, Schiller, Goethe. 2. ed. Leipzig: Meiner, 1923. 
